\title{
The Effect of Pyruvate and Acetate on the Rate of Decrease in Optical Density of Suspensions of Pseudomonas aeruginosa in Sodium, Potassium or Sodium-Potassium Phosphate Buffers
}

\author{
BY F. BERNHEIM \\ Department of Physiology and Pharmacology, Duke University Medical Centre, \\ Durham, North Carolina, U.S.A.
}

(Received 18 September 1963)

\begin{abstract}
SUMMARY
The rate of decrease in optical density (increase in size of organisms) was determined in washed suspensions of a strain of Pseudomonas aeruginosa after they were added to potassium, sodium, or potassium + sodium phosphate buffers. The rate was increased by the addition of pyruvate or acetate. The maximal effect of pyruvate occurred in potassium + sodium buffer; of acetate in potassium buffer. Rate changes were also dependent on $\mathrm{pH}$ value and osmotic pressure.
\end{abstract}

\section{INTRODUCTION}

Mager, Kuczynski, Schatzberg \& Avi-Dor (1956) were the first to show that changes in osmotic pressure of the medium caused changes in size of several Gramnegative bacteria and these changes could be measured by a light-scattering method. Packer \& Perry (1961) found that light-scattering changes in suspensions of Escherichia coli were dependent on energy supplied by oxidizable substrates, and Bernheim (1963) showed that such changes in Pseudomonas aeruginosa reflected the size and density of the organisms and that the rate of change was affected by the cation present and by the integrity of the membrane. The following is a further study of cation and substrate effects.

\section{METHODS}

A strain of Pseudomonas aeruginosa which has been maintained in the laboratory for 15 years, was grown at $34^{\circ}$ for $24 \mathrm{hr}$ in Difco nutrient broth. The organisms were centrifuged down and washed twice with distilled water; in this process they lost potassium (Bernheim, 1963). They were finally suspended in distilled water and the concentration adjusted for estimation of light absorption in a Coleman junior spectrophotometer at $490 \mathrm{~m} \mu$ so that the initial optical density varied no more than $10 \%$ between experiments. However, the results obtained were similar when the number of organisms was doubled or halved. It was not possible to free the organisms of all sodium and potassium, small amounts of which, estimated in a flame photometer, were present in the suspensions. To $2.5 \mathrm{ml}$. of either a salt or sucrose solution. $\mathbf{0 . 5} \mathrm{ml}$. of suspension was added and the optical density read immediately. After $1 \mathrm{~min}$. either $\mathrm{NaCl}$, sodium acetate, or sodium pyruvate in $0 \cdot 1 \mathrm{ml}$. was added, mixed, and the change in optical density determined every 
30 sec. for the next $5 \mathrm{~min}$. This strain of $\boldsymbol{P}$. aeruginosa oxidizes acetate and pyruvate with a minimum latent period and they are thus suitable substrates for short-term experiments. The amount of sodium (0.2-0.28 mg.) added with the substrate did not apparently affect the results. For instance, when potassium phosphate was used as the osmotic agent, the rate of change in optical density with sodium acetate was the same as that with potassium acetate. All experiments were done at $23^{\circ}$. The optical density is expressed in terms of the scale reading, $-\log T \times 1000$. In the range of suspension concentrations used, transmission plotted against number of organisms gave a straight line. It was therefore assumed that the same relationship held between transmission and size of organism.

\section{RESULTS}

The effect of added substrate on the optical density change is rapid. When $0.035 \mathrm{M}-\mathrm{Na}+\mathrm{K}$ phosphate buffer $(\mathrm{pH} 7 \cdot 7)$ was used as the osmotic agent, the addition of $0.1 \mathrm{ml}$. water caused a 6 -unit decrease in the next $30 \mathrm{sec}$. When $1 \cdot 0$, 0.1 , or $0.01 \mathrm{mg}$. of sodium pyruvate was added, each concentration in $0.1 \mathrm{ml}$, a 10-unit decrease occurred, but $0.001 \mathrm{mg}$. was no better than water. Table 1

\section{Table 1}

The effect of several concentrations of sodium pyruvate and sodium acetate on the change in optical density (OD) 5 min. after their addition to organisms suspended in $0.035 \mathrm{~m}-\mathrm{Na}+\mathrm{K}$ phosphate buffer $(\mathrm{pH} 7 \cdot 7)$.

$\begin{array}{lcc}\text { Compound } & \text { Mg added } & \begin{array}{c}\text { Decrease } \\ \text { in OD }\end{array} \\ \mathrm{NaCl} & 1 \cdot 1 & 10 \\ \mathrm{Na} \mathrm{pyruvate} & 0 \cdot 5 & 75 \\ & 1 \cdot 0 & 87 \\ \text { Na acetate } & 2 \cdot 0 & 86 \\ & 0 \cdot 74 & 40 \\ & 1 \cdot 48 & 49 \\ & 2 \cdot 96 & 63 \\ & 4 \cdot 44 & 77\end{array}$

The effect of $1.0 \mathrm{mg}$. sodium pyruvate and $0.74 \mathrm{mg}$. sodium acetate on the change in optical density (OD) 5 min. after their addition to organisms suspended in buffer $(\mathrm{pH} \mathrm{7 \cdot 0)}$.

$\begin{array}{lcc}\text { Compound } & \begin{array}{c}\text { Decrease } \\ \text { in OD in } \\ 0 \cdot 035 \mathrm{M}- \\ \text { buffer }\end{array} & \begin{array}{c}\text { Decrease } \\ \text { in OD in } \\ 0 \cdot 053 \mathrm{M}- \\ \text { buffer }\end{array} \\ \begin{array}{l}\text { Na pyruvate } \\ \text { Na acetate }\end{array} & 60 & 66 \\ & 59 & 33\end{array}$

compares the effect of several concentrations of acetate and pyruvate on the change in optical density $5 \mathrm{~min}$. after their addition to organisms in $0.035 \mathrm{M}-\mathrm{Na}+\mathrm{K}$ phosphate buffer ( $\mathrm{pH} 7 \cdot 7)$. Maximal rate was obtained with $1.0 \mathrm{mg}$. pyruvate but had not been obtained with $4.44 \mathrm{mg}$. acetate, 6 times the molar concentration. Table 1 also shows that as the osmotic pressure of the medium increased, pyruvate was more effective in increasing the size of organism than was equimolar acetate.

Table 2 and Fig. 1 show the effect of cations and $\mathrm{pH}$ value on the activity of acetate and pyruvate. In the presence of equimolar amounts of sodium and potassium ions, the acetate effect at $\mathrm{pH} 6 \cdot 2$ was better than at $\mathrm{pH} 7 \cdot 7$, but the reverse was true for pyruvate. The acetate effect was maximal when potassium phosphate was used as the osmotic agent; it was virtually absent when sodium phosphate was used, i.e. it was little better than $\mathrm{NaCl}$. The pyruvate effect was maximal when sodium and potassium phosphates were used and was minimal but still appreciable when only sodium ion was present. Thus acetate required potassium 


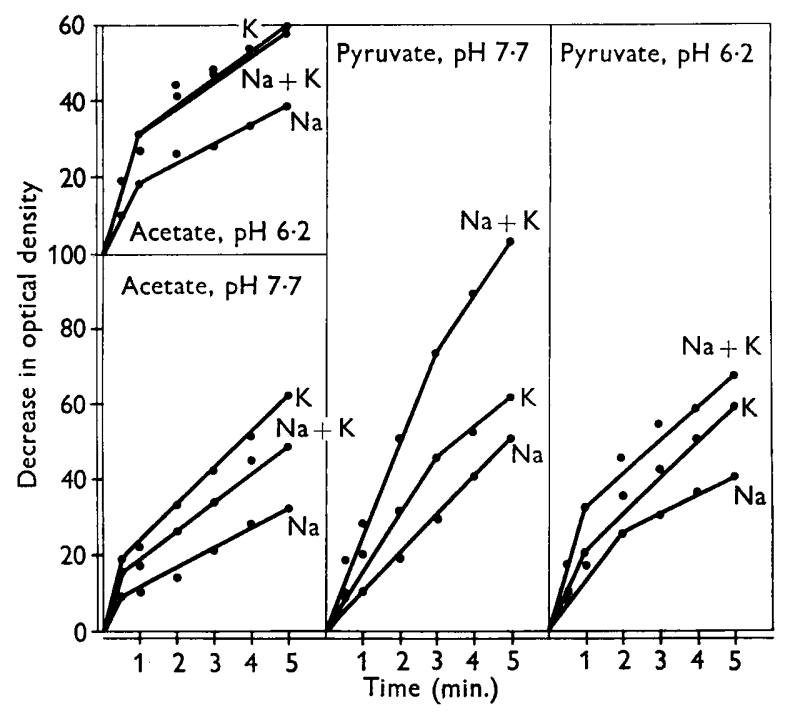

Fig. 1. The rate of decrease in optical density after the addition of $1.0 \mathrm{mg}$. sodium pyruvate or $0.74 \mathrm{mg}$. sodium acetate to organisms in potassium, sodium, or sodium + potassium buffers, $0.035 \mathrm{M}$, at $\mathrm{pH} 6.2 \mathrm{or} 7 \cdot 7$. When $0.6 \mathrm{mg}$. $\mathrm{NaCl}$ was added instead of the substrates the curve obtained was identical with that of acetate in sodium buffer at pH 7.7.

Table 2. The effect of $1.0 \mathrm{mg}$. sodium pyruvate or $0.74 \mathrm{mg}$. sodium acetate at $\mathrm{pH} 7 \cdot \mathbf{7}$ or 6.2 on the decrease of optical density $(O D)$ after the organisms were suspended in 0.035 M-potassium, sodium or sodium + potassium buffers. The figures represent the decrease 5 min. after the addition of the substrates

$\begin{array}{ccccc}\text { Buffer cation } & \text { pH value } & \overbrace{\mathrm{NaCl}} & \text { Acetate } & \text { Pyruvate } \\ \mathbf{K} & \mathbf{7 \cdot 7} & \mathbf{3 3} & 62 & 61 \\ \mathrm{~K} & \mathbf{6 \cdot 2} & \mathbf{3 0} & \mathbf{6 0} & \mathbf{5 9} \\ \mathrm{Na} & \mathbf{7 \cdot 7} & \mathbf{3 1} & \mathbf{3 2} & \mathbf{5 0} \\ \mathrm{Na} & \mathbf{6 \cdot 2} & \mathbf{3 2} & \mathbf{3 8} & \mathbf{4 0} \\ \mathrm{Na}+\mathrm{K} & \mathbf{7 \cdot 7} & \mathbf{3 5} & \mathbf{4 8} & \mathbf{1 0 3} \\ \mathrm{Na}+\mathrm{K} & \mathbf{6 \cdot 2} & \mathbf{3 2} & \mathbf{5 8} & \mathbf{6 7}\end{array}$

ions whereas pyruvate acted in the presence of either sodium or potassium but was more efficient when both were present. These differences may be correlated with the rates of oxidation of the two compounds under the different conditions. Fig. 2 shows the relative oxidation rates. There is a correlation but it is not perfect. At pH $6 \cdot 2$ and $7 \cdot 7$ acetate was oxidized more rapidly in potassium than in sodium buffer and this correlates with its effect on the optical density. But at both pH values it was oxidized most rapidly in the sodium + potassium mixture, but this was not reflected in the rate of change of optical density. At both $\mathrm{pH}$ values pyruvate was oxidized most rapidly in the sodium + potassium mixture and this correlates with its effect on the optical density. Pyruvate was oxidized less rapidly in sodium than in potassium buffer and this also correlates with the optical density 
changes. Finally, at $\mathrm{pH} 6 \cdot 2$, acetate in potassium buffer was oxidized more slowly than pyruvate, yet the effect of both on the rate of change of optical density at this $\mathrm{pH}$ value was the same. Relative oxidation rates are therefore important but may not be the only factor involved.

It has been shown by DeTurk \& Bernheim (1960) that chelators of ferrous iron inhibit the oxidation of a number of substrates by the Pseudomonas aeruginosa used here. Washed organisms were incubated for $60 \mathrm{~min}$. with $50 \mu \mathrm{g}$. $/ \mathrm{ml}$. of $2,2^{\prime}$-dipyridyl before addition to $0.035 \mathrm{M}-\mathrm{Na}+\mathrm{K}$ phosphate $(\mathrm{pH} 7 \cdot 7)$ and the decrease in optical density compared with the control. When acetate or pyruvate was added, the 5-min. values showed a $28 \%$ inhibition. But when $\mathrm{NaCl}$ was added instead of these substrates, the slow decrease in optical density was not inhibited. The endogenous mechanism responsible for this slow decrease was not affected by the chelator.

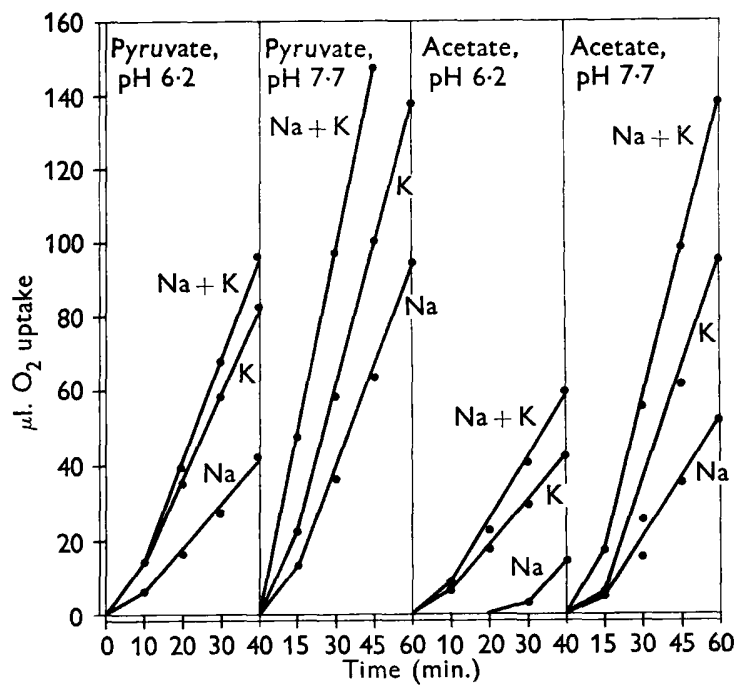

Fig. 2. The oxidation of $1.0 \mathrm{mg}$. sodium pyruvate and $0.74 \mathrm{mg}$. sodium acetate in potassium, sodium, or sodium + potassium buffers, $0.035 \mathrm{M}$, at $\mathrm{pH} 6 \cdot 2$ and $7 \cdot 7$.

\section{DISCUSSION}

Increase in organism size after osmotic shrinking with inorganic salts must be the result of water intake with or without ions. There is no feasible way of measuring ion penetration into the organism after the addition of large salt concentrations. Loss from the liquid is too small to determine and washing causes progressive loss of intracellular ions so that no definitive value can be obtained. Ions, however, accelerate the swelling. As shown previously (Bernheim, 1963) osmolar sucrose shrinks the organisms to the same extent as inorganic salts, but the subsequent swelling is at a much slower rate unless a salt is added. A potassium salt increases the rate more than sodium which in turn is more effective than lithium, caesium, or rubidium. The cations thus show a relative specificity in affecting water transport or in being themselves transported with their water of hydration.

It is generally agreed that energy is required for swelling after osmotic shrinking. 
It is therefore not surprising that oxidizable substrates increase the rate. (In the previous paper it was shown that when salts of organic acids, whether substrates or not, were used as osmotic agents, the subsequent swelling was more rapid than when osmolar concentrations of salts of inorganic acids were used. The reason for this is not clear but damage to the membrane by high concentrations of organic anions is a possibility.) In the present experiments the organic acids were used in substrate amounts, their effect on the rate of swelling is, under most conditions, correlated with their oxidation rates, and cations affect the two substrates differently. Moreover, substrates such as succinate and other Krebs cycle compounds which show a latent period before being oxidized have little effect on swelling rate during the 5 min. observation period.

Neither pyruvate nor acetate is oxidized in the absence of added cation, i.e. in Tris buffer and Tris-neutralized compounds. Thus oxidation is linked with the presence of cations, specifically sodium and potassium (lithium and caesium are much less effective) and swelling is also linked with their presence. It is as yet impossible to decide whether cations are necessary for the transport of pyruvate, acetate, and water or whether pyruvate and acetate accelerate the transport of cations and water. Finally, pyruvate may be metabolized to acetate and the greater effectiveness of pyruvate on swelling rate may be the result of the presence of both anions.

\section{REFERENCES}

Bernheim, F. (1963). Factors which affect the size of the organisms and the optical density of suspensions of Pseudomonas aeruginosa and Escherichia coli. J. gen. Microbiol. 30, 53.

DETURK, W. E. \& BernHeim, F. (1960). The inhibition of enzyme induction and ammonia assimilation in Pseudomonas aeruginosa by sulfhydryl compounds and by cobalt, and its reversal by iron. Archs. Biochem. 90, 218.

Mager, J., Kuczynski, M., Schatzberg, G. \& Avi-Dor, Y. (1956). Turbidity changes in bacterial suspensions in relation to osmotic pressure. J. gen. Microbiol. 14, 69.

Packer, L. \& Perry, M. (1961). Energy-linked light-scattering changes in Escherichia coli. Archs. Biochem. 95, 379. 